\title{
Continuous subcutaneous insulin infusion: an approach to achieving normoglycaemia
}

\author{
J C PICKUP, H KEEN, J A PARSONS, K G M M ALBERTI
}

British Medical fournal, 1978, 1, 204-207

\section{Summary and conclusions}

A study was performed to examine the feasibility of achieving long periods of near-normoglycaemia in patients with diabetes mellitus by giving a continuous subcutaneous infusion of insulin solution from a miniature, battery-driven, syringe pump. Twelve insulindependent diabetics had their insulin pumped through a subcutaneously implanted, fine nylon cannula; the basal infusion rate was electronically stepped up eightfold before meals. The blood glucose profile of these patients was closely monitored during the 24 hours of the subcutaneous infusion and compared with the profile on a control day, when the patients were managed with their usual subcutaneous insulin. Diet and exercise were standardised on both days.

In five out of 14 studies the subcutaneous insulin infusion significantly lowered the mean blood glucose concentration without producing hypoglycaemic symptoms; in another six patients the mean blood glucose concentration was maintained. As assessed by the $M$ value the level of control was statistically improved in six out of 14 studies by the infusion method and maintained in six other patients.

To assess the effects of blood glucose control on diabetic microvascular disease it will be necessary to achieve long-term normoglycaemia in selected diabetics. The results of this preliminary study suggest that a continuous subcutaneous insulin infusion may be a means of maining physiological glucose concentrations in diabetics. Though several problems remain-for example, in determining the rate of infusion-longer-term studies with the miniature infusion pumps are now needed.

\section{Introduction}

The influence of poor metabolic control of diabetes mellitus on the pathogenesis of some of its complications, particularly diabetic microangiopathy, is controversial. ${ }^{1-3}$ Nevertheless, the last 30 years have seen a strengthening of the belief that these complications would not develop if physiological blood glucose concentrations could be maintained in diabetic patients, and that even if they did develop, restitution of normoglycaemia might slow or even reverse their progression. The scanty

Unit for Metabolic Medicine, Guy's Hospital Medical School, London SE1 9RT

J C PICKUP, BM, DPHIL, research associate and honorary registrar

$\mathrm{H}$ KEEN, MD, FRCP, professor of human metabolism

National Institute for Medical Research, Mill Hill, London NW7 1AA

$\mathrm{J}$ A PARSONS, $\mathrm{BM}, \mathrm{BCH}$, head of laboratory of endocrine physiology and pharmacology

Chemical Pathology and Human Metabolism Unit, General Hospital, Southampton SO9 4XY

K G M M ALBERTI, MRCP, MRCPATH, professor of chemical pathology and human metabolism evidence for and against this view is based mainly on retro-듬 spective clinical studies, one recent prospective study, ${ }^{4}$ and $\frac{\bar{\omega}}{\sigma}$ observations on spontaneous and experimental diabetes in $\triangle$ animals. The answer to this question will provide not onlyo further understanding of the pathogenesis of the complications but also a guide to the intensity with which we try to achieve? metabolic normality in our patients. The practical difficulty of $\overrightarrow{\vec{\omega}}$ achieving normoglycaemia leaves the question unanswered.

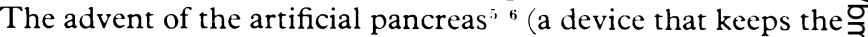
blood glucose concentration within a desired range by a servocontrolled intravenous infusion of insulin or glucose, or both, $\dot{\sigma}$ at rates computed from on-line measurements of the blood $\vec{\circ}$ glucose concentration) has made it possible to maintain physio- N logical blood glucose concentrations in diabetics for limited periods. But long-term use of the artificial pancreas is restricted by its bulk and intricacy. Almost equally effective blood glucose control has been attained more simply and in ambulant patients $\infty$ by intravenous insulin infusion with increased rates for meals $\stackrel{c}{\stackrel{c}{2}}$ but without the glucose sensing and servocontrol mechanism. ${ }^{9}$ Time limits are set to both approaches by the problems inherent in the use of the intravenous route.

We have been exploring the feasibility of dual-rate, low- $\overrightarrow{0}$ volume, subcutaneous insulin infusions to try to overcome the ${ }^{\infty}$ limitations of the intravenous route while maintaining the constancy and flexibility of a controllable but robust and reliable external delivery system. We report here a preliminary evaluation of this approach and its potential for achieving long-term near-normoglycaemia in selected diabetic patients.

\section{Patients and methods}

SUBCUTANEOUS INFUSION SYSTEM

Insulin was delivered by a portable, battery-driven, miniature syringe pump (a prototype of the Mill Hill infuser, weighing $159 \mathrm{~g}^{11}$ ). The pump measured $14.5 \times 2.2 \times 4.2 \mathrm{~cm}$ and was fitted with a $2-\mathrm{ml}$ disposable plastic syringe. It was constructed to deliver at two rates- - ? a slow basal rate of $47, \mu \mathrm{h}$ and an eightfold higher rate $(375, \mu 1 \mathrm{~h})$. The high rate was engaged by pressing a small button on the side of 0 the pump and the rate automatically returned to the basal level after $\vec{\partial}$ 17 minutes.

Insulin was delivered via a fine (external diameter $0.4 \mathrm{~mm}$, internal $D$ diameter $0.19 \mathrm{~mm}$ ) nylon cannula (Portex Ltd, Hythe, Kent) im- 음 planted in the subcutaneous tissue of the anterior abdominal wall in the right subcostal region. The area was cleaned with antiseptic solution and then two points, about $6 \mathrm{~cm}$ apart, were anaesthetised $\omega$ with a small bleb of $1^{\circ}$ "lignocaine solution. The cannula was attached to the syringe of insulin, filled to the tip, and fitted into the pump.e An introducing needle (gauge 16 Medicut, length $6.9 \mathrm{~cm}$, with plastic $\frac{\mathrm{C}}{\mathbb{D}}$ surround removed, Sherwood Medical Industries) was inserted subcutaneously through one anaesthetised area and pushed through 0 to the exterior through the other. The cannula was then fed into the $\bar{O}$ lumen of the needle via the tip, using sterile forceps. Removal of $\overrightarrow{\mathbb{D}}$ the introducing needle left the cannula implanted subcutaneously. Its $\frac{\rho}{\mathbb{Q}}$ position was adjusted so that the tip was about midway between $\varrho$ needle entry and exit point. The cannula was secured with tape and the pump attached to the patient by bandage or a harness.

The concentration of insulin in the infusion pump was adjusted for each patient according to the total daily dose on his or her normal regimen (usually $100^{\circ}$, and occasionally more or less than this, as $\frac{\bar{c}}{\partial}$ listed in table I). Actrapid monocomponent insulin (Novo Industri) was used throughout as the infusion fluid, diluted as necessary with $0 \cdot 154 \mathrm{~mol} 1 \mathrm{saline}$. The minimum concentration was $26 \mathrm{U} \mathrm{ml}$ and the range of basal infusion rates 0.9 to $3.2 \mathrm{U}$ h. 


\section{PATIENTS AND PROTOCOL}

After full explanation of the research nature of the study 12 insulin-dependent diabetics with various degrees of control were recruited. Their age, known duration of diabetes, sex, and insulin dose are listed in table I. After exploratory studies the following protocol was devised and applied to most patients. Patients were admitted on the evening of day 1 and the procedure explained. Day 2 was a control day during which they received their normal insulin regimen. Blood was withdrawn from an indwelling intravenous Teflon cannula every 30 minutes (every two hours during the night) for glucose estimation by the glucose oxidase method adapted for an autoanalyser. The cannula was kept patent by flushing with $0.154 \mathrm{~mol} / \mathrm{l}$ saline (without anticoagulant). Blood was also withdrawn every two hours for measuring intermediary metabolites, glucagon, etc (the results will be reported elsewhere).

A standard breakfast was given to each patient so that the hyperglycaemic response to this could be compared on the control and infusion days within and between patients. The meal consisted of $46 \mathrm{~g}$ bread, $16 \mathrm{~g}$ butter, $150 \mathrm{ml}$ milk, $22 \mathrm{~g}$ cornflakes, and tea or coffee without sugar. The total carbohydrate content was $50 \mathrm{~g}$ and the energy content was $1.7 \mathrm{MJ}(416 \mathrm{kcal})$. The rest of the day's meals fo'lowed the prescribed diabetic diet for that patient.

On day 3 the diabetics who injected insulin twice a day received their morning dose of insulin but not the evening dose; the patient using a single dose was given a reduced dose for the morning injection of insulin. During the evening the subcutaneous cannula was inserted and the pump started at the slow rate. This provided an overnight run-in period, during which the blood glucose was brought into the normal range for the start of the infusion study the next morning, day 4.
During day 4 the infusion pump was switched to the high rate either 15 minutes (cases 1,5 (experiment A), 6, 7, 10 (experiment $A$ ), and 11) or 30 minutes before the standard breakfast, lunch, and supper. Snacks were given at mid-morning, mid-afternoon, and bedtime but without increasing the insulin delivery rate. Venous blood samples were withdrawn as on the control day. Patients were freely ambulant throughout the study and attempts were made to match exercise on control and infusion days.

The results were assessed by comparing the 24-hour blood glucose profiles on days 2 and 4 (see fig 1 ) and the mean blood glucose concentrations on these days. We also calculated the $M$ value using the formula of Schlichtkrull et al, ${ }^{11}$ as modified by Service et al ${ }^{12}$ :

$$
M=\frac{\sum\left({ }^{\left.10 \log _{10} \frac{B G}{4.44}\right)^{3}}\right.}{n}
$$

where $B G$ is the blood glucose concentration (in $\mathrm{mmol} / \mathrm{l}$ ) of each sample and $\mathrm{n}$ is the number of samples.

\section{Results}

Fig 1. shows the comparable blood glucose profiles of these patients on their normal insulin regimen and after subcutaneous insulin infusion.

Table II compares the mean blood glucose and $M$ values on the control and infusion days. In cases $1,2,3,4$, and $5(\mathrm{~B})$ diabetic control was significantly improved by subcutaneous infusion, as assessed by the mean blood glucose concentration on the two days (2-tailed $t$ test). The $M$ value shown is a quantitative index of diabetic control, the range for normal subjects being $0-1 \cdot 0$, and it increases

TABLE I-Clinical features of patients

\begin{tabular}{|c|c|c|c|c|c|c|}
\hline \multirow{2}{*}{$\begin{array}{l}\text { Case } \\
\text { No }\end{array}$} & \multirow{2}{*}{$\underset{\text { (years) }}{\text { Age }}$} & \multirow[t]{2}{*}{ Sex } & \multirow{2}{*}{$\begin{array}{c}\text { Duration of } \\
\text { diabetes } \\
\text { (years) }\end{array}$} & \multicolumn{2}{|c|}{ Type of insulin and normal daily dose (units) } & \multirow{2}{*}{$\begin{array}{l}\text { Dose of insulin } \\
\text { infused ( } \% \text { of } \\
\text { control day) }\end{array}$} \\
\hline & & & & am & $\mathrm{pm}$ & \\
\hline $\begin{array}{r}1 \\
2 \\
3 \\
4 \\
5 \\
6 \\
7 \\
8 \\
9 \\
10 \\
11 \\
12\end{array}$ & $\begin{array}{l}48 \\
53 \\
53 \\
57 \\
29 \\
42 \\
63 \\
36 \\
19 \\
31 \\
33 \\
39\end{array}$ & $\begin{array}{l}\mathrm{F} \\
\mathrm{M} \\
\mathrm{M} \\
\mathrm{M} \\
\mathrm{M} \\
\mathrm{M} \\
\mathrm{M} \\
\mathrm{M} \\
\mathrm{M} \\
\mathrm{M} \\
\mathrm{F} \\
\mathrm{F}\end{array}$ & $\begin{array}{l}32 \\
20 \\
18 \\
27 \\
0 \cdot 5 \\
15 \\
37 \\
6 \\
10 \\
11 \\
23 \\
30\end{array}$ & $\begin{array}{l}\text { Actrapid } 16 \\
\text { Soluble insulin } 52 \\
\text { Lente } 56 \\
\text { Soluble insulin } 16 \text {, isophane } 12 \\
\text { Actrapid } 10 \text {, Rapitard } 10 \\
\text { Actrapid } 44 \\
\text { Soluble insulin } 8 \text {, isophane } 16 \\
\text { Soluble insulin } 44 \\
\text { Rapitard } 20 \\
\text { Soluble insulin } 24 \text {, isophane } 16 \\
\text { Soluble insulin 18, soluble insulin } 10 \text { (noon) } \\
\text { Soluble insulin } 10 \text {, isophane } 6\end{array}$ & $\begin{array}{l}\text { Actrapid } 20 \\
\text { Soluble insulin } 44 \\
\text { Soluble insulin } 8 \text {, isophane } 8 \\
\text { Actrapid } 5 \text {, Rapitard } 15 \\
\text { Actrapid } 32 \\
\text { Soluble insulin } 12 \text {, isophane } 14 \\
\text { Soluble insulin } 20 \\
\text { Rapitard } 20 \\
\text { Soluble insulin 16, isophane } 8 \\
\text { Soluble insulin 12 } \\
\text { Soluble insulin 10, isophane } 6\end{array}$ & $\begin{array}{r}100 \\
100 \\
121 \\
200 \\
100 \\
100 \\
75 \\
100 \\
100 \\
100 \\
65 \\
193\end{array}$ \\
\hline
\end{tabular}

$$
\begin{array}{ll}
B=\text { Breakfast } & .0830-0930 \\
L=\text { Lunch } & 1230-1330 \\
E=\text { Evening meal } & 1830-1900
\end{array}
$$



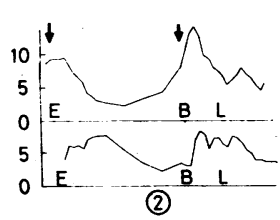

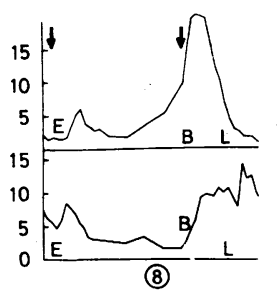

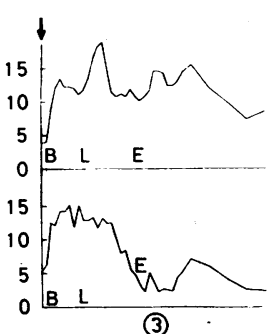
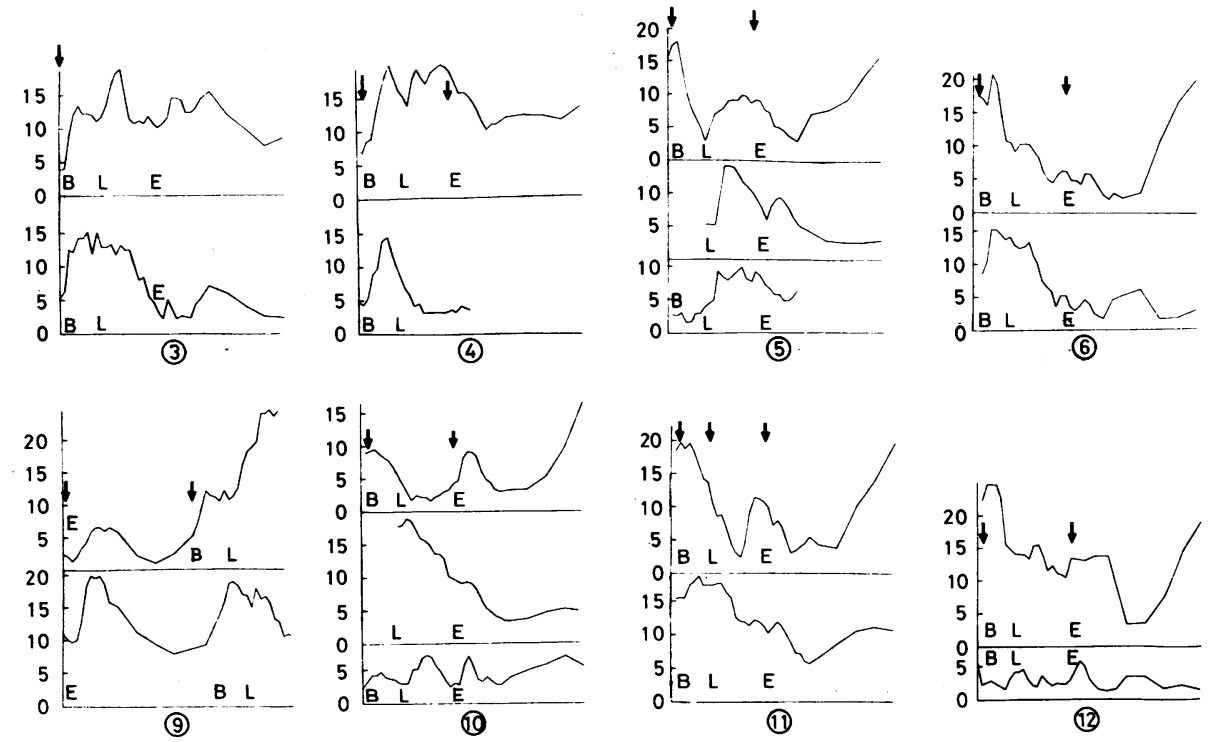

FIG 1-Comparison of blood glucose profiles on normal and infusion days. For each patient the upper panel shows the blood glucose profile on the normal insulin regimen and the lower panel(s) the profile after continuous subcutaneous insulin infusion. In cases 5 and 10 the infusion experiment $A$ is middle panel and experiment $B$ is lower panel. Injection times on control day are shown by arrows.

Conversion: SI to traditional units-Glucose: $1 \mathrm{mmol} / 1 \approx 18 \mathrm{mg} / 100 \mathrm{ml}$. 
TABLE II-Comparison of mean blood glucose concentration $( \pm S D)$ and $M$ value $( \pm S D)$ on control day and subcutaneous infusion day

\begin{tabular}{|c|c|c|c|c|c|c|}
\hline \multirow{2}{*}{$\begin{array}{l}\text { Case } \\
\text { No }\end{array}$} & \multicolumn{3}{|c|}{$\begin{array}{l}\text { Mean blood glucose } \\
(\text { mmol l) }\end{array}$} & \multicolumn{3}{|c|}{$M$ value } \\
\hline & Control day & Infusion day & $P$ & Control day & Infusion day & $P$ \\
\hline $\begin{array}{l}1 \\
2 \\
3 \\
4 \\
5(B)\end{array}$ & 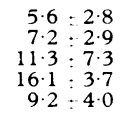 & $\begin{array}{l}3.6=1.3 \\
5.3=1.7 \\
3.9=4.6 \\
5.1=3.7 \\
5.9=2.5\end{array}$ & $\begin{array}{l}<0.001 \\
<0.001 \\
<0.001 \\
<0.001 \\
<0.002\end{array}$ & $\begin{array}{r}12: 15 \\
25: 34 \\
84: 48 \\
176: 80 \\
43: 64\end{array}$ & $\begin{array}{c:c}12: 19 \\
5 \cdot 0: 5 \cdot 3 \\
52: 53 \\
31: 30 \\
18: 23\end{array}$ & $\begin{aligned} & \text { NS } \\
&<0.002 \\
&<0.05 \\
&<0.01 \\
& \text { NS }\end{aligned}$ \\
\hline $\begin{array}{c}5(\mathrm{~A}) \\
6 \\
7 \\
8 \\
9 \\
10(\mathrm{~B})\end{array}$ & $\begin{array}{r}8 \cdot 6: 3 \cdot 8 \\
8 \cdot 8: 5 \cdot 6 \\
6 \cdot 5: 4 \cdot 0 \\
6 \cdot 4: 6 \cdot 9 \\
13 \cdot 2: 7 \cdot 6 \\
5 \cdot 6: 3 \cdot 4\end{array}$ & $\begin{array}{r}7 \cdot 7: 3 \cdot 3 \\
7 \cdot 6: 4 \cdot 6 \\
7 \cdot 4: 2 \cdot 3 \\
6 \cdot 4: 3 \cdot 5 \\
14 \cdot 5: 3 \cdot 6 \\
4 \cdot 2: 1 \cdot 5\end{array}$ & $\begin{array}{l}\text { NS } \\
\text { is } \\
\text { is } \\
\text { NS } \\
\text { NS }\end{array}$ & $\begin{aligned} 43 & : 64 \\
67 & =94 \\
50 & =34 \\
85 & =110 \\
141 & : 169 \\
24 & -36\end{aligned}$ & $\begin{array}{r}28: 38 \\
45: 52 \\
21: 17 \\
33: 35 \\
135: 80 \\
3 \cdot 9: 5 \cdot 2\end{array}$ & 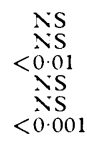 \\
\hline $10(\mathrm{~A})$ & $\begin{array}{l}4 \cdot 8: 2 \cdot 6 \\
9 \cdot 2: 5 \cdot 9\end{array}$ & $\begin{array}{r}9 \cdot 7: 5 \cdot 0 \\
18 \cdot 1: 3 \cdot 9\end{array}$ & $\begin{array}{l}<0.005 \\
<0.001\end{array}$ & $\begin{array}{l}24: 36 \\
73: 92\end{array}$ & $\begin{aligned} 70 & : 86 \\
230 & : 104\end{aligned}$ & $\begin{array}{l}\text { NS } \\
<0.001\end{array}$ \\
\hline 12 & $13 \cdot 8: 2 \cdot 8$ & $5 \cdot 9: 1 \cdot 0$ & $<0.001$ & $144=177$ & $28: 34$ & $<0.01$ \\
\hline
\end{tabular}

NS $=$ Not significant $(\mathbf{P}>0.05)$.

Conversion: SI to traditional units-Glucose: $1 \mathrm{mmol} 1=18 \mathrm{mg} 100 \mathrm{ml}$.

with extreme values of both hypoglycaemia and hyperglycaemia. The $M$ values in these five patients showed fewer significant improvements than the mean blood glucose values, largely because of the increase in value caused by the low blood glucose concentrations.

The insulin dose infused subcutaneously is shown in the last column of table I as a percentage of the total daily dose on the control day. Some of the patients (cases 1, 4, 5(B) and 7) were studied for only 12 hours because of technical failure towards the end of the experiment (usually the cannula became kinked or was pulled out during the night). In these cases the mean blood glucose and $M$ values were compared with those in the corresponding 12 hours on the control day.

Fig 2 illustrates in more detail the blood glucose profiles of case 1 on the normal regimen and during subcutaneous infusion.

In a second group of patients (cases 5(A), 6, 7, 8, 9, and 10(B)) there was no statistically significant difference $(P>0.05, t$ test $)$ in the mean blood glucose concentration between the two days. But the $M$ values for control for two of these patients were significantly improved (Wilcoxon-Mann-Whitney rank sum test). The profile in one of these patients (case 10(B)) is shown in detail in fig 3, which shows that despite an insignificant fall in mean blood glucose con-

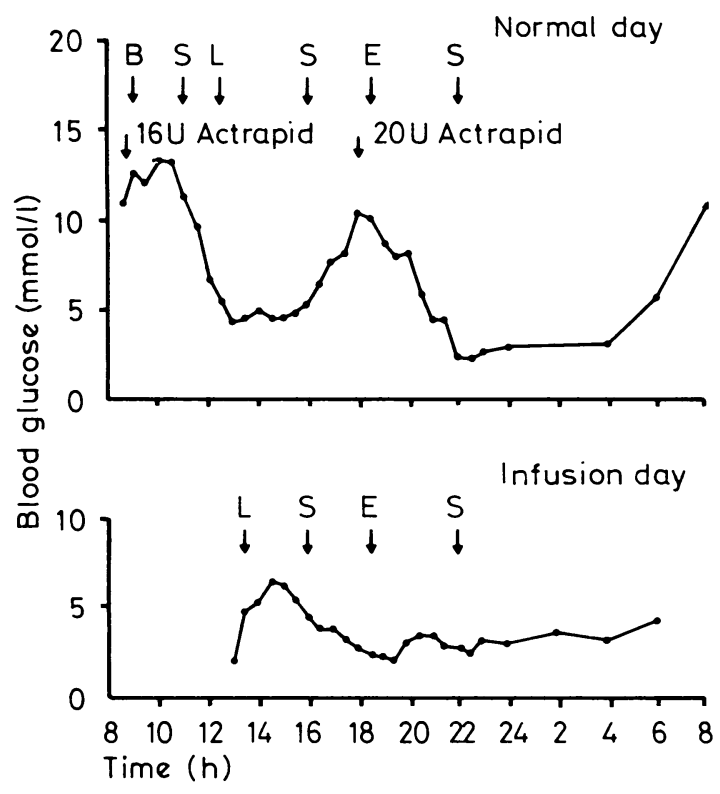

FIG 2-Case 1. Blood glucose profiles on control and infusion days. Upper panel shows control day with Actrapid insulin injected as indicated. $\mathrm{B}=$ Standard breakfast. $\mathrm{L}=$ Lunch. $\mathrm{E}=$ Evening meal. $\mathrm{S}=$ Snack. Lower panel shows blood glucose profile during subcutaneous insulin infusion. Pump was switched to high rate 15 minutes before meals for 17 minutes. Basal infusion rate was $1 \cdot 2 \mathrm{U} / \mathrm{h}$, calculated on $100 \%$ of total daily dose on control day.

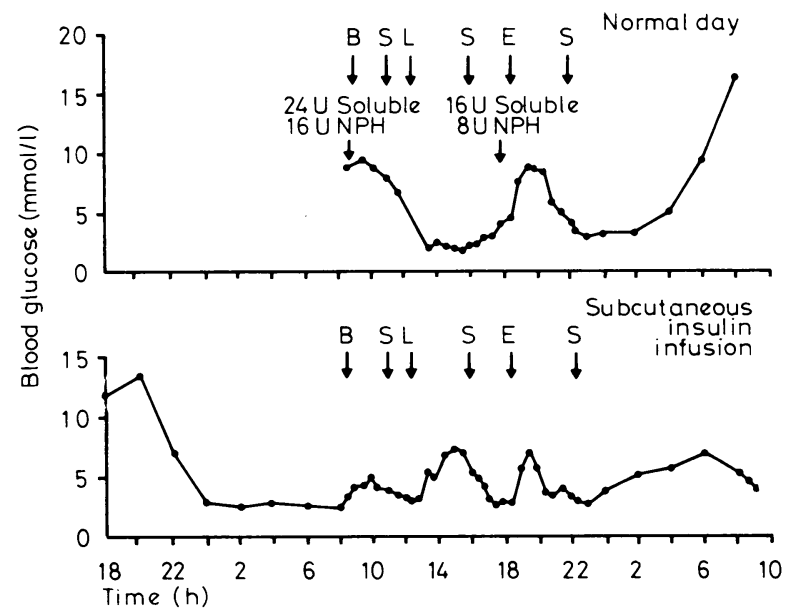

FIG 3-Case 10. Blood glucose profile (experiment B) on control and infusion days. Upper panel shows control day with twice-aday soluble and isophane insulin (NPH) injected as indicated. $\mathrm{B}=$ Standard breakfast. $\mathrm{L}=$ Lunch. $\mathrm{E}-$ Evening meal. $\mathrm{S}=$ Snack. Lower panel shows blood glucose profile during the subcutaneous insulin infusion. First 14 hours was run-in period at basal rate $(2 \cdot 1 \mathrm{U} / \mathrm{h}$, calculated on $100 \%$ of the total daily dose on the control day), and experimental day began at 0800 . Pump was switched to high rate 30 minutes before meals for 17 minutes.

centration the $M$ value was reduced from 24 to 3.9 by subcutaneous infusion with the same total dose of insulin as on the control day.

Two patients (cases $10(\mathrm{~A})$ and 11 ) experienced worse control during $\mathscr{N}$ infusion; in both cases the mean blood glucose concentration was $\frac{7}{2}$ significantly higher during the infusion and in case 11 the $M$ value was also significantly increased. In case 11 we infused only $65 \%$ of N the normal insulin dose and there was no run-in period. This illustrates N the problems of choosing the correct infusion dose and the importance of preinfusion to bring the blood glucose down into the normal range before starting the infusion. In case 10 the absence of an overnight run-in in experiment $\mathrm{A}$ was remedied in experiment $\mathrm{B}$.

The problem of deciding on the infusion dose is illustrated by? case 12 in table II. Here the greatly improved blood glucose control 0 was achieved at the expense of frequent hypoglycaemic symptoms

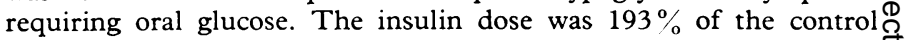
regimen, chosen arbitrarily on the basis of poor control on the normal $\mathbb{\Phi}$ day, although the patient was known on clinical grounds to be a "brittle" diabetic-that is, she suffered unpredictable glycaemic episodes. A lower infusion rate might well have achieved a better 8 result, though the underlying metabolic instability of this patient? may also have disturbed the response to infusion.

Five patients were on a mixture of short- and intermediate-acting insulin (cases $4,5,7,10$, and 12), which would be considered by many as the best routine subcutaneous treatment. Nevertheless, the mean blood glucose concentration was further improved in two of these patients (cases 4 and $5(B)$ ). 


\section{Discussion}

To test the effects of blood glucose control on diabetic microvascular disease it will be necessary to select patients with early and potentially reversible manifestations and to achieve fairly long-term near-normoglycaemia. Multiple subcutaneous injections of soluble insulin can greatly improve blood glucose control but are limited by patient acceptability and introduce the possibility that hypoglycaemia might be caused by a comparatively large subcutancous pool of insulin. Intravenous infusion systems, such as the artificial pancreas, are unsuitable for extended periods of normoglycaemia because of the bulk and the cost of the machinery and because of problems of infection, thrombosis, and cannula tolerance. Continuous subcutaneous insulin delivery using the Mill Hill infuser is a feasible way of controlling the blood glucose concentration in diabetics, and in some patients near-normoglycaemia was achieved for the comparatively short periods tested. The extension of this system to long-term control is our next aim, but several problems will first have to be solved.

Success in achieving normoglycaemia will clearly depend on choosing the correct dose of insulin to infuse. We have shown that in patients with reasonable control on their normal injection day it is possible to improve the mean blood glucose concentration and $M$ value even further by administering the same dose by continuous subcutaneous infusion. In other patients, particularly those whose control is usually imperfect, the optimal infusion dose is difficult to select and may have to be predetermined by titrating the blood glucose concentration against multiple subcutancous injections of soluble insulin before the infusion starts. With a continuous intravenous infusion most patients can be controlled on less than the usual 24-hour dose, but with the subcutaneous route requirements are higher, possibly because of immobilisation or destruction of some of the insulin at the subcutancous site. ${ }^{13} 1$ Diabetics with wide and unpredictable changes in their insulin requirements may not be suitable for this approach, though we have so far made only a few obscrvations in this group. The degree to which the dose has to be augmented for meals may also vary from person to person, though our standard eightfold increase seems to have fitted most needs. Self-monitoring may enable some patients to use a high rate or basal rate of the pump more or less often, according to need.

Blood glucose control is complex and can be viewed as the result of at least three functions: the mean blood glucose concentration, the variability of glucose values about the mean (which can be assessed by the standard deviation or the mean amplitude of glycaemic excursions ${ }^{1:}$ ), and the unpredictability or brittleness of glucose values. The $M$ value is some measure of the first two factors, and, as we have shown here, it can sometimes be improved even when the mean blood glucose concentration remains the same. Brittleness is by definition difficult to quantify but the day-to-day variation index ${ }^{15}$ provides one means of assessing it.

Many of our patients achieved a good reduction in blood glucose values, with concentrations often falling to $2 \cdot 2-2 \cdot 8$ $\mathrm{mmol} 1(40-50 \mathrm{mg} / 100 \mathrm{ml})$, without experiencing hypoglycaemic symptoms. This raises the question of whether such asymptomatic chemical hypoglycaemia is harmful. ${ }^{3}$

Continuous subcutaneous infusion differs from ordinary depot injection treatment in that there may never be very much insulin within the patient. This probably explains why most patients do not develop overwhelming hypoglycaemia. Furthermore, a few days of near-normoglycaemia will probably improve the defective counterregulatory response to hypoglycaemia seen in the previously poorly controlled diabetic.

Binder has shown that the rate of absorption of subcutaneously injected radioiodinated insulin in diabetics varies with the site of injection, injection volume, concentration, and tissue blood flow. ${ }^{16}$ Animal studies also indicate that about half of a bolus subcutaneous insulin injection has no biological effect (fall in blood glucose) and is perhaps destroyed by proteolytic enzymes in the subcutaneous tissue ${ }^{1314}$ (unpublished observations). Manipulation of these factors may improve the rate of absorption of continuously infused insulin and the control at meal times. Moreover, absorption kinetics will determine any subcutaneous pooling of insulin during the day and thereby the suitability for long-term use.

We have implanted the subcutaneous cannula in normal subjects for up to 10 days without any discomfort, or infection at the site, but tolerance of the cannula may obviously be important for long-term studies.

The results of our early studies have encouraged us to extend our studies to assess the longer-term domiciliary use of this system in selected diabetics and to investigate the effect of improved diabetic control on the course of some of the microangiopathic complications.

We thank the sister and staff nurses of the metabolic ward, Guy's Hospital, and the metabolic ward dietitian, Miss Helen Brown, for their invaluable help in performing this study. Mr K G Kilbourn and Mr E Regina provided skilful technical help. Mr R Blows constructed the special dual-rate versions of the Mill Hill Infuser. This work was supported by a grant from the British Insulin Manufacturers.

\section{References}

${ }^{1}$ Cahill, G F, Etzwiler, D D, and Freinkel, N, New England fournal of Medicine, 1976, 294, 1004.

- Siperstein, M D, et al, New England Fournal of Medicine, 1977, 296, 1060.

"Ingelfinger, F J, New England Fournal of Medicine, 1977, 296, 1228.

' Job, D, et al, Diabetes, 1976, 25, 463.

Albisser, A M, et al, Diabetes, 1974, 23, 397.

6 Mirouze, J L, et al, Diabetologia, 1977, 13, 273.

- Slama, G, et al, Diabetes, 1974, 23, 732

Deckert, T, and Lorup, B, Diabetologia, 1976, 12, 573

${ }^{9}$ Genuth, S, and Martin, P, Diabetes, 1977, 26, 571 .

11" Parsons, J A, Rothwell, D, and Sharpe, J E, Lancet, 1977, 1, 77.

11 Schlichtkrull, J, Munck, O, and Jersild, M, Acta Medica Scandinavica, $1965,177,95$.

1.2 Service, F J, et al, Diabetes, 1970, 19, 644.

${ }_{13}$ Parsons, J A, et al, British Fournal of Pharmacology, 1977, 59, 489P.

14 Parsons, J A, et al, British fournal of Pharmacology, 1977, 59, 524P.

${ }_{15}$ Molnar, G D, Taylor, W F, and Ho, M M, Diabetologia, 1972, 8, 342.

${ }^{16}$ Binder, C, Acta Pharmacologica Toxicologica, 1969, 27, suppl No 2, p 1.

(Accepted 4 November 1977) 